\title{
Endophytic fungi, Beauveria bassiana and Metarhizium anisopliae, confer control of the fall armyworm, Spodoptera frugiperda (J. E. Smith) (Lepidoptera: Noctuidae), in two tomato varieties
}

Lizzy A. MwamburiD

\begin{abstract}
Background: The fall armyworm, Spodoptera frugiperda (J. E. Smith) (Lepidoptera: Noctuidae), is an important pest of tomatoes that reduces yield and fruit quality resulting in losses of up to $100 \%$. The pest has developed resistance to chemical insecticides, therefore necessitating alternative control measures. The entomopathogenic fungi (EPF) Beauveria bassiana and Metarhizium anisopliae have been exploited extensively for biological control of the insect pests of economic importance.

Results: The potential of B. bassiana (Bals.) Vuillemin (Hypocreales: Cordycipitaceae) (BbC1) and M. anisopliae (Metchn.) Sorokin (Hypocreales: Clavicipitaceae) (M150) to persist as endophytic EPF in two tomato varieties, Matina and Harzfeuer, which spread within host tissues and protect plants against larval attack of S. frugiperda was evaluated. Tomato seedlings were inoculated by dipping roots in either BbC1 or M150 spore suspensions (10 ${ }^{8}$ spores/ $\mathrm{ml}$ ). The qPCR analyses revealed the presence of both fungi in $>65 \%$ of the tested samples. Second-instar larvae of $S$. frugiperda were introduced onto inoculated plants that revealed the presence of fungal DNA and noninoculated plants, 14 days after inoculation. Treating tomato plants with the EPF resulted in reducing weights and slowing larval development of Spodoptera. Larvae fed on BbC1 and M150-treated Matina significantly reduced weights than those treated with Harzfeuer tomato plants. The tomato variety Matina conferred enhanced level of resistance to the S. frugiperda larvae, further aggravated by the presence of both fungi through dietary stress resulting in slow development and reduce larval weight.
\end{abstract}

Conclusion: These results may serve the tomato production systems and the S. frugiperda integrated management programs.

Keywords: Fall armyworm, Spodoptera frugiperda, Beauveria bassiana, Metarhizium anisopliae, Endophyte, Tomato varieties

Correspondence: lizzy.mwamburi@uoeld.ac.ke; lizzymwamburi@hotmail.com Department of Biological Sciences, University of Eldoret, P.O. Box 1125-30100, Eldoret, Kenya

(c) The Author(s). 2021 Open Access This article is licensed under a Creative Commons Attribution 4.0 International License, which permits use, sharing, adaptation, distribution and reproduction in any medium or format, as long as you give appropriate credit to the original author(s) and the source, provide a link to the Creative Commons licence, and indicate if changes were made. The images or other third party material in this article are included in the article's Creative Commons licence, unless indicated otherwise in a credit line to the material. If material is not included in the article's Creative Commons licence and your intended use is not permitted by statutory regulation or exceeds the permitted use, you will need to obtain permission directly from the copyright holder. To view a copy of this licence, visit http://creativecommons.org/licenses/by/4.0/. 


\section{Background}

Tomato is the second largest grown and arguably most consumed vegetable in Kenya (Government of Kenya (GoK) 2018). Production of tomato is threatened by infestation with the invasive fall armyworm Spodoptera frugiperda (J. E. Smith) (Lepidoptera: Noctuidae). S. frugiperda is an economic pest of $>60$ different crops including sorghum, rice, wheat, beans, cotton, potatoes, and tomatoes. It reduces yield and fruit quality of tomatoes grown in greenhouse and open fields and may result in losses of up to $100 \%$. Chemical sprays are minimally effective due to the resistance of S. frugiperda to many pesticides and also because of the pest's development that takes place inside the plant or the soil, and therefore, they are out of reach of pesticides. The damages caused by larvae begin after transplanting the seedlings to the field and can extend throughout the plant's development.

The entomopathogenic fungi (EPF) Beauveria bassiana (Bals.) Vuillemin (Hypocreales: Cordycipitaceae) (Bb) and Metarhizium anisopliae Sorokin (Hypocreales: Clavicipitaceae) (Ma) are ubiquitous and biological control agents of a wide range of insects. They have been exploited extensively in biological control programs. The potential of these fungal pathogens to exist as endophytes in plants and to protect their colonized host plants against the primary herbivore pests has been widely reported. $B b$ has been reported to control many crop pests such as stem borers, beetles, aphids, mites, termites, whiteflies, mealy bugs, and thrips (Shah and Pell 2003). $B b$ has been reported as an endophytic colonizer of several plant species including corn (Zea mays), potato (Solanum tuberosum), cocoa (Theobroma cacao), date palm (Phoenix dactylifera), opium poppy (Papaver somniferum), coffee (Coffea arabica), banana (Musa spp.) tissue cultures, sorghum (Sorghum bicolor), bean (Phaseolus vulgaris), cotton (Gossypium hirsutum), pumpkin (Cucurbita maxima), tomato (Solanum lycopersicum), jute (Corchorus olitorius), pine (Pinus radiata), squash (Cucurbita pepo), artichoke (Cynara scolymus), grapevine (Vitis vinifera), oilseed rape (Brassica napus), tobacco (Nicotiana tabacum), soybean (Glycine max), cassava (Manihot esculenta), and wheat. The endophytic potential of $B b$ has also been reported to reduce pests' damage to plants indirectly by inhibiting insect development and reproduction or directly by causing insect mycosis resulting in mortality (Rondot and Reineke 2018) while in exchange receiving nutrition and refuge from plants (Saikkonen et al. 2004).

The insect-pathogenic fungus, Metarhizium, is a common inhabitant of soils worldwide and has been studied and used as an insect pathogen for biological control (Clifton et al. 2018). However, this fungus is not only an insect pathogen but it also readily colonizes the plant rhizosphere (St. Leger et al. 2011). In contrast to the high number of studies on the endophytic $B b$, only a few studies have been conducted on the endophytic Metarhizium isolates. For instance, Metarhizium sp. has been reported as an endophyte of corn (Kabaluk and Ericsson 2007), tomato (Garcia et al. 2011), oilseed rape (Batta 2013), and cassava (Greenfield et al. 2016), and its endophytic activity against insect pests has been reported in oil seed rape against larvae of Plutella xylostella larvae (Batta 2013).

The present study aimed to evaluate the persistence of two EPF isolates as endophytes in tomato plants, which spread within host tissues and protect the plants against larval infestation of $S$. frugiperda.

\section{Main text \\ Methods \\ Fungal isolates}

Two fungal isolates; $\mathrm{BbC1}$ and M150, available in the laboratory, at the Department of Crop Sciences, Agricultural Entomology, Georg-August University, Germany, were used in the study. Spores were harvested from 2week old PDA cultures, by adding two drops of Tween 20 to the culture, and then gently scraping the conidia and placing into a $200-\mathrm{ml}$ flask containing $100 \mathrm{ml}$ sterile water. The conidia were harvested by vortexing, followed by filtration of the spore suspension, using a Buchnertype funnel through a 2-layered filter paper $(90 \mathrm{~mm})$ to remove mycelial fragments and aggregated conidia. The spore densities were adjusted to $10^{8} / \mathrm{ml}$.

\section{Insect species}

Second larval instar of S. frugiperda were obtained from Bayer Crop Science. The larvae were reared on tomato seedlings for several generations at $25{ }^{\circ} \mathrm{C}, \mathrm{RH} 70 \%$, and at a photoperiod of $8 \mathrm{~h}$. The adults were fed on $30 \%$ honey solution and newly hatched larvae were transferred to $200 \mathrm{ml}$ disposable plastic cups and reared on artificial medium (Gupta et al. 2005) until reaching the second larval instar.

\section{Plant species}

Two tomato varieties, Harzfeuer and Matina, originated in the Middle East were sown in pots containing a mixture of peat- moss and sand (3:1). Plants used in experiments were at a similar size and were randomly assigned to each treatment. In three separate repeated experiments, 36 seedlings of each tomato variety were left to grow under greenhouse conditions until the 3rd leaf growth stage. After shaking off excess soil, the roots were rinsed, using running tap water. The roots of 12 seedlings of each tomato variety were dipped in $25 \mathrm{ml}$ of either BbC1 or M150 spore suspensions $\left(10^{8} / \mathrm{ml}\right)$ for 2 min. Another 12 plants from each variety were dipped in 
$25 \mathrm{ml}$ of sterile distilled water and used as controls. These plants were then transplanted into $11-\mathrm{cm}$ plastic pots containing the same soil and sand mixture and left to grow under greenhouse conditions for 7 days and used for bioassays.

\section{Determination of endophytic colonization Re-isolation of fungi on selective media}

In order to assess the potential of $\mathrm{BbC} 1$ and M150 to endophytically colonize tomato plants, 4 leaf samples/ plant were taken both from the inoculated and control plants every 7 days, cut into 4-6 pieces; their surfaces were sterilized, using $70 \%$ alcohol for $3 \mathrm{~min}$, $5 \%$ sodium hypochlorite for $2 \mathrm{~min}$, and then $70 \%$ alcohol for $2 \mathrm{~min}$; and finally, they were rinsed in sterile distilled water 3 times, and then dried out on sterile filter paper. The fragments were then placed on modified selective medium consisting of $39 \mathrm{~g}$ PDA, $100 \mathrm{mg} \mathrm{NaCl}, 50 \mathrm{mg}$ chloramphenicol, and $0.5 \mathrm{mg}$ crystal violet per $1 \mathrm{l}$. The plates were incubated at $25{ }^{\circ} \mathrm{C}$ for 2 weeks. Three replicates of randomly selected leaf fragments of each treatment were assessed for fungal colonization and repeated with each experimental set-up.

\section{Molecular analysis of fungal colonization in tomato plants}

DNA extraction and real time PCR were used to assess plants $\mathrm{BbC} 1$ and $\mathrm{M} 150$ growth inside plant tissues.

\section{DNA extraction}

The upper 3 newly emerged unfolded leaves leaf samples were picked from inoculated and control plants 10 days after inoculation, and their surfaces were sterilized before freeze-drying and then milled into powder. A 50mg sample of plant material, in a 2-ml Eppendorf tube, was centrifuged and used for DNA extraction. Total DNA was extracted from the plant materials, using the standard cetyltrimethylammonium bromide (CTAB) extraction protocol (Doyle and Doyle 1987) after which the DNA samples were stored overnight in the fridge. Thereafter, the quality of the extracted DNA was checked, using the electrophoresis by adding $5 \mu \mathrm{l}$ of extracted DNA and $2 \mu \mathrm{l}$ loading dye and loading them into $0.8 \%$ agarose gel, which was run for $120 \mathrm{~min}$ at $60 \mathrm{~V}$ then stained with Ethidium bromide and visualized using UV light.

\section{Fungal DNA quantification using the real-time $P C R$}

Specific primers designed for both $\mathrm{BbC} 1$ and M150 were used for optimizing the qPCR protocol. Thereafter, standard curves for both fungi were established with a minimum quantity of 200 femtogram/ $\mu$ l. Diluted $(1 / 10$ and $1 / 20$ ) and un-diluted DNA samples were run alongside with the standards, following the optimized qPCR protocol for quantifying the fungal DNA presence in the tested samples.

\section{Introduction of larvae onto inoculated plants}

Second-instar larvae (4 day old) of S. frugiperda (one per plant) were introduced onto 12 plants, each of inoculated (that tested positive for fungal DNA) and noninoculated plants after 14 days of inoculation. One larva was secured per plant, using a clip-cage, and that was moved onto a different leaf on the same plant every 24 $h$. The plants were arranged in a completely randomized design in a controlled environmental chamber $(25 \pm 1$ ${ }^{\circ} \mathrm{C}, \mathrm{RH} 80 \%$ and $\mathrm{L}$ to $\left.\mathrm{D} 8: 16 \mathrm{~h}\right)$. This set-up was repeated 3 times.

\section{Determination of the effect of endophytes on Spodoptera frugiperda larvae}

The initial weights of Spodoptera larvae were taken before introduction to the plants. Larvae were weighed every 7 days for 21 days. All larvae were removed from both control plants after 21 days, when the larvae of control plants developed into pupae. Larvae feeding on BbC1- and M150-treated tomato plants never pupated. Dead larvae were removed on a daily basis and placed in dishes with moistened filter paper to evaluate for mycosis.

\section{Data analysis}

A factorial ANOVA was used to assess the impact of root-inoculated $\mathrm{BbC1}$ and $\mathrm{M} 150$ tomato plants on larval weights. The dependent variables were the weight of larvae, and factors were tomato variety and fungal treatment. Tukey's test was used for multiple comparisons of means $(P<0.05)$ (Statistica).

\section{Results}

Determination of endophytic colonization

Re-isolation on selective media

Both $\mathrm{BbC1}$ and $\mathrm{M} 150$ were re-isolated in leaf fragments, using selective medium (Table 1). In addition, the fungal DNA detection in the leaves and significant reduction in

Table 1 Presence (\%) of Beauveria bassiana (BbC1) and Metarhizium anisopliae (M150) in leaves of two tomato varieties at different times following root inoculation

\section{Tomato variety}

\begin{tabular}{llllll}
\hline & Matina & & & Harzfeuer & \\
\cline { 2 - 3 } \cline { 5 - 6 } & $\mathbf{7 ~ d p i}$ & $\mathbf{1 4} \mathbf{~ d p i}$ & & $\mathbf{7 ~ d p i}$ & $\mathbf{1 4} \mathbf{~ d p i}$ \\
\hline B. bassiana & $81.5 \pm 11.7$ & 100 & & $74.5 \pm 11.2$ & 100 \\
M. anisopliae & $87.5 \pm 11.5$ & 100 & & $79.5 \pm 11.6$ & 100
\end{tabular}

Percentages are means of positive scores for three experiments ( \pm SD). Four leaf samples from each plant were taken both from the inoculated and control plants every 7 days and were tested for the presence of the fungi every 7 days. Control plants were negative for B. bassiana and $M$. anisopliae, and therefore the results were not shown. dpi days post inoculation 
weight of S. frugiperda larvae were evidence of fungal presence in the leaves.

\section{Fungal growth quantification using the real-time $P C R$}

The qPCR analyses proved the presence of both fungi, $\mathrm{BbC} 1$ and $\mathrm{M} 150$, and they were found in $>65 \%$ of the tested samples (Fig. 1). Although the detected quantities were so low (even in 1:10 as well as 1:20 dilutions of DNA samples), it was important to note that the sampled leaves for this test were always the upper 3 newly emerged unfolded leaves.

Effect of B. bassiana and M. anisopliae on the weight of S. frugiperda larvae

Treating tomato plants with either BbC1 or M150 resulted in reducing weights of Spodoptera larvae (Table 2, Fig. 2). Weights of the larvae fed on tomato plants, treated with either $\mathrm{BbC1}$ or $\mathrm{M} 150$, significantly differed between tomato varieties and treatments $(P<0.001$ : $\mathrm{df}$ $1)$ than the control plants. Significant interactive effects were also observed between M150-treated tomato plants of either tomato varieties Matina $(P=0.006$ : $\mathrm{df} 1)$ and Harzfeuer $(P=0.014: \mathrm{df} 1)$ varieties compared to the $\mathrm{BbC1}$-treated tomato plants. These differences were observed during weeks 1 and 2, but they were not as apparent as the differences observed in the larval development after 3 weeks of feeding on M150-treated tomato plants (Table 2, Fig. 2).
The obtained results also showed that the weights of larvae, fed on BbC1- or M150-treated Matina tomato variety, were reduced compared to those feeding on either BbC1- or M150-treated Harzfeuer variety (Fig. 2). This was also true at the controls of both plants. For instance, in controls, weights of larvae fed on Matina were reduced by (33\%) more than those fed on the Harzfeuer, while weights of larvae fed on $\mathrm{BbC} 1$-treated Matina plants were reduced $45 \%$ more than those feeding on $\mathrm{BbC} 1$-treated Harzfeuer tomato plants. When S. frugiperda larvae were fed on M150-treated Matina plants, their weights were reduced by $59 \%$ higher than M150treated Harzfeuer plants.

\section{Discussion}

Fungal presence in the leaves was evidenced by reisolation of fungal DNA in the treated leaves and reduced weights of $S$. frugiperda larvae feeding on the treated leaves. Ramirez-Rodriguez and Sánchez-Peña (2016) reported similar results, using endophytic $B$. bassiana in Zea mays acting as a systemic entomopathogen to larvae of S. frugiperda.

The results of the present study revealed that the weights of $S$. frugiperda larvae were affected when the larvae were fed on BbC1 and M150 root-inoculated tomato plants. In addition, none of the larvae fed on either of the tomato varieties could develop beyond the larval stage. Clearly, the development of the larvae was delayed as a result of $\mathrm{BbC1}$ or $\mathrm{M} 150$ fungal treatments of the

\section{$\sum_{1}^{\sqrt[\Xi]{5}}$ \\ M 12345678910111213141516171819202122 M}

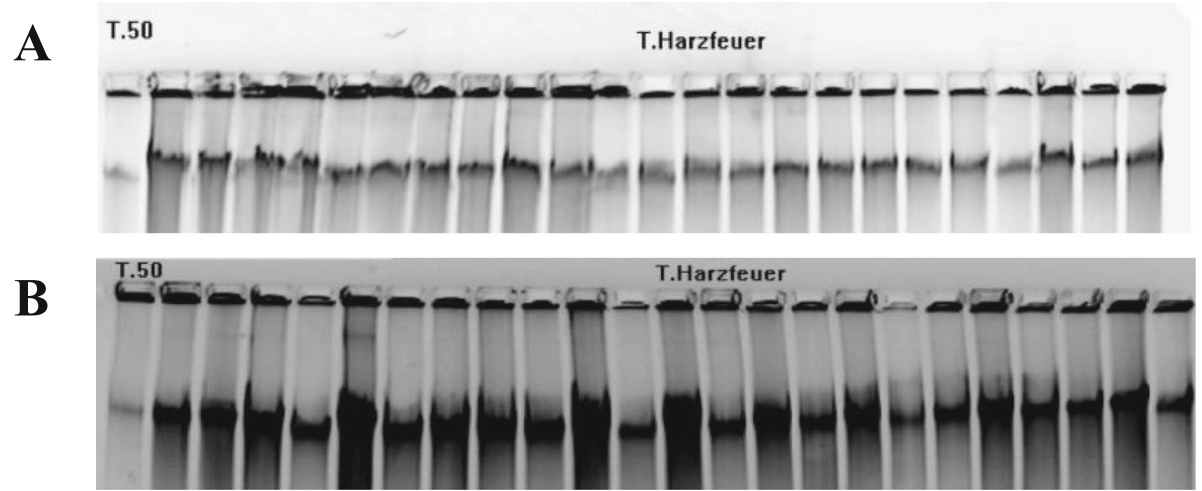

Fig. 1 Total DNA of A. endophytic Beauveria bassiana (BbC1) and B. Metarhizium anisopliae (M150) in on agarose gel in two tomato varieties. $1^{\text {st }}$ and last lanes Marker: Lane 1- 11: Total fungal DNA isolated in Matina tomato variety: Lanes 12 to 22: Total DNA isolated from Harzfeuer tomato variety 
Table 2 Weight gain of Spodoptera frugiperda larvae feeding on root-inoculated tomato varieties (Harzfeuer and Matina) either with Beauveria bassiana (BbC1) or with Metarhizium anisopliae (M150) for 21 days

\begin{tabular}{|c|c|c|c|c|}
\hline \multicolumn{2}{|l|}{ Treatment } & \multicolumn{3}{|c|}{ Mean weight gain of $S$. frugiperda larvae $(\mathrm{mg}) \pm \mathrm{se}^{*}$} \\
\hline \multirow{2}{*}{$\begin{array}{l}\text { Tomato } \\
\text { variety }\end{array}$} & \multirow{2}{*}{$\begin{array}{l}\text { Fungal } \\
\text { treatment }\end{array}$} & \multicolumn{3}{|l|}{ Days } \\
\hline & & 7 & 14 & 21 \\
\hline \multirow[t]{3}{*}{ Matina } & None (control) & $23.40 \pm 2.93 a$ & $110.77 \pm 8.69 \mathrm{ab}$ & $202.78 \pm 19.64 \mathrm{bc}$ \\
\hline & $\mathrm{BbC1}$ & $20.99 \pm 1.70 b$ & $81.29 \pm 11.58 b c$ & $147.18 \pm 28.74 \mathrm{~cd}$ \\
\hline & M150 & $21.35 \pm 1.47 a$ & $70.16 \pm 9.56 c$ & $95.56 \pm 13.56 d$ \\
\hline \multirow[t]{3}{*}{ Harzfeuer } & None (control) & $22.17 \pm 1.92 \mathrm{ab}$ & $127.91 \pm 8.47 a$ & $332.38 \pm 30.14 a$ \\
\hline & $\mathrm{BbCl}$ & $16.98 \pm 1.81 b c$ & $104.40 \pm 17.03 a b$ & $300.78 \pm 29.18 a$ \\
\hline & M150 & $11.34 \pm 1.60 c$ & $72.62 \pm 11.48 c$ & $235.96 \pm 36.08 b$ \\
\hline
\end{tabular}

Means with the same letter within the same column are not significantly different $(P \leq 0.05)$

*Values are means $( \pm$ se) of three replicates of assays each containing 12 larvae \pm se

Calculated from a mean original weight $(3.25 \pm 0.15 \mathrm{mg})$ of 12 larvae

tomato plants, and unlike the larvae feeding on untreated tomato that pupated after 21 days, it did not pupate.

Although non-significant differences were observed between $\mathrm{BbC1}$-treated and $\mathrm{BbC1}$-untreated plants, the results indicated that $\mathrm{BbC} 1$ reduced larval weights by 27 and $9.5 \%$ in Matina and Harzfeuer varieties, respectively. These results are comparable to those reported by Cherry et al. (2004) on the effect of endophytic $B b$ on maize stem borers. The authors demonstrated that even though $\mathrm{Bb}$ exhibited a non-significant reduction in mean larval weights, there was an evidence of reduction in stem borer effect in the maize plants. Reduced growth effects, as a result of $B b$, were also reported for Chortoicetes terminifera by Gurulingappa et al. (2010). Similarly, it was demonstrated that $\mathrm{BbC} 1$-inoculated Matina and
Harzfeuer tomato plants displayed reduced growth effects as a result of infestation with the fall armyworm (unpublished report). Most probably, $B b$ acted as an antagonist against $S$. frugiperda larvae by producing metabolites that reduced insect infestations on their host plants (Jaber and Ownley 2018) or changed the plant defense responses and recruited $B b$ as a defensive strategy against insect herbivore (McKinnon et al. 2018).

Interestingly, S. frugiperda larvae in the control of variety Matina had significantly lower weights than those fed on Harzfeuer. This was further compounded by the presence of $\mathrm{BbC1}$ and $\mathrm{M} 150$ in the variety Matina plant tissues. This indicates that varietal differences of the tomato plants influenced the susceptibility of S. frugiperda larvae to the entomopathogens (Tanada and Kaya 1993). The larvae that fed on Matina-inoculated plants most

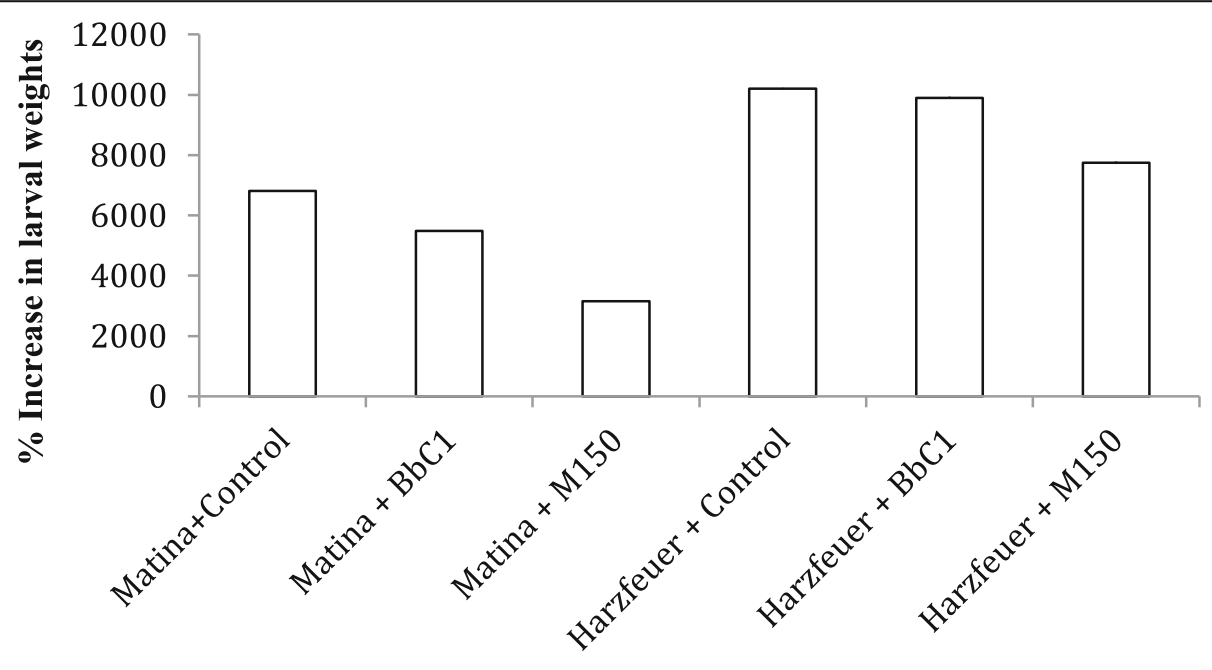

Treatment

Fig. 2 Percent increase in weight of Spodoptera frugiperda larvae after 3wks of feeding on Beauveria bassiana (BbC1) and Metarhizium (M150) root-inoculated tomato (Matina and Harzfeuer) 
probably suffered from the reduced consumption as a result of production of secondary metabolites with antiherbivore properties (Shrivastava et al. 2015), allelochemical (Santiago-Álvarez et al. 2006) changes in the phytosterol profile of plants, or induction of an indirect systemic response (Castillo-Lopez and Sword 2015) that may have affected the feeding behavior in the larvae and growth rate and development of the pest. Furthermore, the presence of endophytic EPF may also influence terpenoid levels in tomatoes, resulting in a strong defense response against insect herbivores (Shrivastava et al. 2015; McCormick et al. 2016). It is therefore possible that the tomato variety Matina increased the susceptibility of S. frugiperda larvae to $\mathrm{BbC1}$ and M150 through dietary stress (Tanada and Kaya 1993), therefore influencing their susceptibility to EPF infection and resulting in reduced development and weight of larvae.

\section{Conclusion}

The present study assessed the influence of 2 tomato varieties on the susceptibility of $S$. frugiperda larvae to $B$. bassiana and $M$. anisopliae. The tomato variety Matina conferred some level of resistance to the S. frugiperda larvae. This effect was further aggravated by the presence of M150 and BbC1. It is important to use this information in $S$. frugiperda integrated management programs.

\section{Abbreviations}

Bb: Beauveria bassiana; BbC1: Beauveria bassiana variety C1; Ma: Metarhizium anisopliae; M150: Metarhizium anisopliae variety 150;

CTAB: Cetyltrimethylammonium bromide

\section{Acknowledgements}

The authors are thankful to The World Academy of Science (TWAS) and Deutsche Forschungsgemeinschaft (DFG) for financial support and the Agricultural Entomology research group, Georg-August Universität, Gottingen, for support during this research.

\section{Author's contributions}

The author read and approved the final manuscript.

\section{Funding}

This research did not receive any specific grant from funding agencies in the public, commercial or not-for-profit sectors.

\section{Availability of data and materials}

The data used and analyzed during this study is available from the author on request.

\section{Ethics approval and consent to participate}

N/A

\section{Consent for publication}

$\mathrm{N} / \mathrm{A}$

\section{Competing interests}

The author declares no conflict of interest.
Received: 30 September 2020 Accepted: 17 December 2020

Published online: 05 January 2021

\section{References}

Batta YA (2013) Efficacy of endophytic and applied Metarhizium anisopliae (Metch.) Sorokin (Ascomycota: Hypocreales) against larvae of Plutella xylostella L. (Yponomeutidae: Lepidoptera) infesting Brassica napus plants. Crop Protect 44:128-134

Castillo-Lopez D, Sword GA (2015) The endophytic fungal entomopathogens Beauveria bassiana and Purpureocillium lilacinum enhance the growth of cultivated cotton (Gossypium hirsutum) and negatively affect survival of the cotton bollworm (Helicoverpa zea). Biol Control 89:53-60

Cherry AJ, Banito A, Djegui D, Lomer C (2004) Suppression of the stem-borer Sesamia calamistis (Lepidoptera; Noctuidae) in maize following seed dressing, topical application and stem injection with African isolates of Beauverio bassiana. Int J Pest Manage 50:67-73

Clifton EH, Jaronski ST, Coates BS, Hodgson EW, Gassmann AJ (2018) Effects of endophytic entomopathogenic fungi on soybean aphid and identification of Metarhizium isolates from agricultural fields. PLOS ONE 13(3):e0194815. https://doi.org/10.1371/journal.pone.0194815

Doyle JJ, Doyle JL (1987) A rapid DNA isolation procedure for small quantities of fresh leaf tissue. Phytochem Bull 19:11-15

Garcia JE, Posadas JB, Perticari A, Lecuona RE (2011) Metarhizium anisopliae (Metchnikoff) Sorokin promotes growth and has endophytic activity in tomato plants. Adv Biol Res 5:22-27

Government of Kenya (GoK) (2018) Kirinyaga County Government. County Integrated Development Plan 2018-2022.

Greenfield M, Gómez-Jiménez MI, Ortiz V, Vega FE, Kramer M, Parsa S (2016) Beauveria bassiana and Metarhizium anisopliae endophytically colonize cassava roots following soil drench inoculation. Biol Control 95:40-48

Gupta G, Rani S, Birah A, Raghuraman M (2005) Improved artificial diet for mass rearing of the tobacco caterpillar, Spodoptera litura (Lepidoptera: Noctuidae). Int J Trop Insect Sci 25:55-58

Gurulingappa P, Sword GA, Murdoch G, McGee PA (2010) Colonization of crop plants by fungal entomopathogens and their effects on two insectpests when in planta. Biol Control 55:34-41

Jaber LR, Ownley BH (2018) Can we use entomopathogenic fungi as endophytes for dual biological control of insect pests and plant pathogens? Biol Control 116:36-45

Kabaluk JT, Ericsson JD (2007) Environmental and behavioural constraints on the infection of wireworms by Metarhizium anisopliae. Environ Entomol 36:1415-1420

McCormick A, Reinecke A, Gershenzon J, Unsicker SB (2016) Feeding experience affects the behavioural response of polyphagous gypsy moth caterpillars to herbivore-induced poplar volatiles. J Chem Ecol 42:382-393

McKinnon AC, Glare TR, Ridgway HJ, Mendoza-Mendoza A, Holyoake A, Godsoe WK, Bufford $J$ (2018) Detection of the entomopathogenic fungus Beauveria bassiana in the rhizosphere of wound-stressed Zea mays plants. Front Microbiol 9:1161

Ramirez-Rodriguez D, Sánchez-Peña SR (2016) Endophytic Beauveria bassiana in Zea mays: pathogenicity against larvae of fall armyworm, Spodoptera frugiperda. Southwest Entomol 41:875-878

Rondot Y, Reineke A (2018) Endophytic Beauveria bassiana in grapevine Vitis vinifera $(\mathrm{L}$.) reduces infestation with piercing-sucking insects. Biol Control 116: 82-89

Saikkonen K, Wäli P, Helander M, Faeth SH (2004) Evolution of endophyte-plant symbioses. Trends Plant Sci 9:275-280

Santiago-Álvarez C, Araujo Maranhão E, Maranhão E, Quesada-Moraga E (2006) Host plant influences pathogenicity of Beauveria bassiana to Bemisia tabaci and its sporulation on cadavers. BioControl 51:519-532

Shah PA, Pell JK (2003) Entomopathogenic fungi as biological control agents. Appl Microbiol Biotechnol 61:413-423

Shrivastava G, Ownley BH, Augé RM, Toler H, Dee M, Vu A, Köllner TG, Chen F (2015) Colonization by arbuscular mycorrhizal and endophytic fungi enhanced terpene production in tomato plants and their defence against a herbivorous insect. Symbiosis 65:65-74

St. Leger RJ, Wang C, Fang W (2011) New perspectives on insect pathogens. Fungal Biol Res 25:84-88

Tanada Y, Kaya HK (1993) Insect Pathology. Academic Press, San Diego, p 666

\section{Publisher's Note}

Springer Nature remains neutral with regard to jurisdictional claims in published maps and institutional affiliations. 